Egypt. Acad. J. biolog. Sci., 2 (2): 29- 36 (2010)

Email: egyptianacademic@yahoo.com

Received: $29 / 6 / 2010$
F. Toxicology \&Pest control

ISSN: 2090 - 0791

www.eajbs.eg.net

\title{
Morphological effects of some insect growth regulators on Musca domestica, (Diptera, Muscidae).
}

\author{
Khalil, M.S.; Assar, A. A.; Abo El-Mahasen, M. M. and Mahmoud, S.H.. \\ Faculty of Science, Menofia University
}

\begin{abstract}
The current work was carried out to evaluate the morphological effects of insect growth regulators e.g. : applaud (buprofezin), consult (hexaflumuron) and match (lufenuron) as chitin synthesis inhibitors (CSIs), mimic (tebufenozide) as ecdysone agonist (EA) and admiral (pyripyroxyfen) as juvenile hormone analogue (JHA) against the housefly, $M$. domestica. Various morphological aberrations were induced in larvae, pupae and adults of $M$. domestica. The highest percentage of larval deformities caused by mimic, (can not molt or shrinked). Consult gave the highest percentage of malformation in the resulting pupae (C. shaped, elongated, distorted, two constricted, tapering anterior and broad posterior, cylindrical adult uncompleted). Admiral and mimic induced high percentage of abnormalities in the adult flies (small size body and curved legs, crumbled wings and curved abdomen). Larval-pupal intermediates and pupal-adult intermediates were induced as a result of these treatments.
\end{abstract}

Keywords: Insect growth regulators, Musca domestica

\section{INTRODUCTION}

The house fly, Musca domestica is the most common and widely distributed mechanical vector of several pathogenic organisms of human and animals. Resistance insects have been recorded for most insecticide. The use of IGRs against the house fly are considered environmentally safer alternatives to broad-spectrum insecticides because of their low toxicity to human, little likelihood that insects would develop resistance to compounds that mimic their own hormones and specificity for their insect targets. Thus, the application of IGRs remains one of promise for the future.

\section{MATERIALS AND METHODS}

The strain of insects was obtained from Research Institute of Medical Entomology, Dokki, Giza, Egypt. The colony was maintained according to Hashem and Youssef, (1991).The eggs were collected and transferred to larval medium, which contain wheat bran
(655 gm.) + Milk powder (50 gm.)+yeast powder (38 gm.)+ Tap water $(600 \mathrm{ml}$.$) . The pupae were$ transferred into cages until adult emergence. Different concentrations, $(10,100,1000$ and $2000 \mathrm{ppm})$ of insect growth regulators, buprofezin (applaud), hexaflumuron (consult), lufenuron (Match), tebufenzoide (Mimic) and pyriproxyfen (Admiral) were prepared by adding water. First instars larvae were divided into five groups, each consists of 20 larvae, put in plastic cups containing media which exposed to selected concentration. The morphological changed were recorded for larval, pupal and adult stages.

\section{RESULTS AND DISCUSSIONS}

Treatment of $1^{\text {st }}$ larval instars of $M$. domestica with various concentrations of the tested IGRs gave rise to noticeable larval, pupal and adult abnormalities. The different abnormal forms in Table (1), can be described as follows:- 
All tested IGRs induced larval deformities. The highest percentage of larval deformities caused by mimic, which was 3,5 and $6 \%$ at 10,100 and 1000 ppm, respectively. In the survived larvae two forms of abnormalities were demonstrated,

Some larvae can't molt completely \{plate (1) fig (B) .
Some larvae with small sized \{plate (1) fig (C) \}.

Schaefer and Wilder (1973) reported that $\mathrm{JH}$ interfered with tyrosine metabolism resulting in a darkening of the cuticle of $C$. pipiens, $C$. quinquefasciatus and Aedes nigiomaculatus.

Table 1: Morphogenic effects of the tested IGRs against $M$. domestica as $1^{\text {st }}$ larval instar.

\begin{tabular}{|c|c|c|c|c|c|c|}
\hline IGRs & $\begin{array}{l}\text { Conc. } \\
\text { ppm }\end{array}$ & $\begin{array}{l}{ }^{*} \text { Malformed } \\
\text { larvae \% }\end{array}$ & $\begin{array}{c}\text { *Larval pupal } \\
\text { intermediaries } \\
\%\end{array}$ & $\begin{array}{l}* \star \text { Malformed } \\
\text { pupae } \%\end{array}$ & $\begin{array}{c}{ }^{*} \text { Pupal-adult } \\
\text { intermediaries } \\
\% \\
\end{array}$ & $\begin{array}{l}* \star * \text { Malformed } \\
\text { adult } \%\end{array}$ \\
\hline \multirow{4}{*}{ Applaud } & 10 & 1 & 1 & 2.01 & 6.11 & 3 \\
\hline & 100 & 2 & 3 & 3.25 & 8.3 & 5 \\
\hline & 1000 & 3 & 4 & 4.38 & 19.22 &. \\
\hline & 2000 & 5 & 6 & 6 & 23 & - \\
\hline \multirow{4}{*}{ Consult } & 10 & 1 & 2 & 40.2 & 14 & 2 \\
\hline & 100 & 3 & 3 & 56.03 & 18 & 5.09 \\
\hline & 1000 & 4 & 5 & 78 & 21.03 & $\cdot$ \\
\hline & 2000 & 5 & 6 & 100 & 22 & - \\
\hline \multirow{4}{*}{ Match } & 10 & 1 & 3 & 15.03 & 13 & 1.2 \\
\hline & 100 & 2 & 4 & 21.01 & 24.37 & 3.15 \\
\hline & 1000 & 4 & 5 & 33.5 & 30.12 & . \\
\hline & 2000 & 5 & 7 & 50.12 & 38.11 & - \\
\hline \multirow{4}{*}{ Mimic } & 10 & 3 & 2 & 4 & 15.1 & 4.2 \\
\hline & 100 & 5 & 3 & 16 & 18.02 & 7.19 \\
\hline & 1000 & 6 & 5 & 50.21 & 22 & . \\
\hline & 2000 & - & - & $\therefore$ & - & $\therefore$ \\
\hline \multirow{4}{*}{ Admiral } & 10 & 1 & 4 & 12.12 & 15.11 & 6 \\
\hline & 100 & 2 & 5 & 38 & 22.04 & 8 \\
\hline & 1000 & - & 7 & 50 & 30 & - \\
\hline & 2000 & - & - & 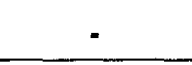 & $\cdot$ & - \\
\hline
\end{tabular}

Similar malformations were reported on $M$. domestica with other IGRs, such as dimilin (El-Kordy, 1985), dimilin, BAY SIR and altosid (Bakr, 1986) and diflubenzuron and penfluron (Shafi et al., 1987) .Darvas et al. (1998) noticed molting disturbances (e.g. hanging larval exuivum, head capsule slippage failure) and a more intensive sclerotization and melanization of the thorax of $A$. aegypti when treated with methoxyfenozide.

All tested IGRs induced larval pupal intermediates. Admiral gave the highest percentage of malformed larval 
- pupal intermediates, which induced 4, 5 and $7 \%$ at 10,100 and $1000 \mathrm{ppm}$, respectively. The puparia of these forms were incomplete with retained parts of the last larval cuticle \{plate (1) fig (D). Similar larval -pupal intermediate was induced by other IGRs on the same species, such as, dimilin (El-Kordy,1985); diflubenzuron and penfluron (Shafi et al,1987); IGI,DC-902, denate, dimilin and amix-500 (Youssef et al.,1990); IKI 7899,BAY-SIR; and methoxyfenozide and pyriproxyfen (Assar and Abo-Shaeshae,2004).

These larval- pupal intermediates failed to complete the pupal period and died soon. Carton et al. (1998) stated that treatment of $S$. exigua larvae with methoxyfenozide led to induction of premature, lethal, larval molt, presence of a double head capsule and appearance of larval pupal intermediate They stated that methoxyfenotide caused the larval thorax to bloat on the dorsoventral sides resulting in a larvalpupal intermediate of A. aegypti. All tested IGRs induced malformations in the pupae of $M$. domestica. Consult gave the highest percentage of malformation in the resulting pupae, which elicited 40.20, 56.03, 78.00 and $100 \%$ at $10,100,1000$ and $2000 \mathrm{ppm}$, respectively. Whereas the lowest percentage was obtained by applaud, which induced 2.01, 3.25, 4.38 and 6\% at 10, 100, 1000 and 2000ppm, respectively. The other tested IGRs were comparable.

Six types of abnormalities that occurred in the pupae: Some pupae took C. shaped (plate (2) fig $(B, C)$, elongated \{plate (2) fig $(\mathrm{D}, \mathrm{E})$, distorted \{plate (3) (A,B,D)\} pupae with conspicuous contractions in their puparia; rod-like larvifrom \{plate (4) fig (A) \}, tapering anterior and broad posterior $\quad$ plate (4)fig(B) $\}$ and cylindrical \{plate (4 )fig (C,D)\} and that they failed to transform to adult stage.

Other IGRs induced similar malformations in the pupae of $M$. domestica, TH 6040 (diflubenzuron) [Wright (1974), El-Kordy (1985), and Shafi et al. (1987)]; BAY SIR (Moustafa,1991); dimilin, BAY SIR and altosid (Bakr,1986); IGI, DC 902, denate, dimilin and amix 500 (Youssef et al.,1990); diflubenzuron and pyriproxyfen (Shalaby, 1994); and methoxyfenozide \& pyriproxyfen (Assar and Abo-Shaeshae, 2004).

All tested IGRs induced pupal-adult intermediates. Match, admiral and mimic gave the highest percentage of malformations. Match induced 13, 24.37, 30.12and $38.11 \%$ pupal-adult intermediates at 10 , 100, 1000 and 2000ppm respectively. Deformed pupae failed to complete their metamorphosis properly which could not emerge completely and remain concealed in the puparia until they die. Consequently incomplete adult ecolsion dominated. In some cases the head and thorax ecolsed while in other cases, the head, thorax and part of the abdomen with the fore wings were released but the rest of the body still attached to the puparia (Plate 5). Other IGRs induced larval-pupal intermediates on M.domstica, BAY SIR (Moustafa, 1991); diflubenzuron and pyriproxyfen (Shalaby, 1994); and methoxyfenozide \& pyriproxyfen (Assar and Abo-Shaeshae, 2004)

All tested IGRs induced adult malformations. Admiral and mimic induced high percentage of abnormalities. Admiral elicited 6 and $8 \%$ abnormalities at 10 and $100 \mathrm{ppm}$, respectively, while mimic caused 4.2 and $7.19 \%$ abnormalities at 10 and 100 ppm, respectively. The tested IGRs induced adult with small sized body and curled legs \{(plate (6) fig (C and D)\}, some adults were with crumpled wings while others were with curved abdomen $\{$ (plate (6), Fig (E, F) $\}$. The 
same abnormalities were reported by some investigators on the same insect species using other IGRs, JHA (Cerf and Georghiou, 1974); diflubenzuron (El-Kordy, 1985); dimilin, BAY SIR and altosid (Baker, 1986); diflubenzuron (Shafi et al., 1987); IGI -DC 902, denate, dimilin and amix500 (Youssef et al., 1990); BAY SIR (Moustafa., 1991); diflubenzuron and pyriproxyfen (Shalaby, 1994); pyriproxyfen (Osman 1998); and pyriproxyfen and methoxyfenozide (Assar and Abo- Shaeshae., 2004). Carton et al. (1998) found that treatment of S.exigua larvae with methoxyfenozide led to malformation in wings, the emerging adults often had problem in discarding the pupal exuvium.

Application of pyriproxyfen to the German cockroach, Blattella germanica $\quad(10-100 \mu \mathrm{g}) \quad$ induced molting of nymphs into supernumerary nymph, (Reid et al., 1994). They said that pyripoxyfen and fenoxycarb induced significant developmental delays and levels of morphogenetic wing.

\section{REFERENCE}

Assar, A.A. and Abo-Shaeshae, .A.A. (2004): Effect of two insect growth regulators, methoxyfenozide and pyrlproxyfen on the house fly, Musca domestica vicina (Diptera: Muscidae). J. Egypt. Ger. Soc. Zoo 44(E): 19-42.

Bakr, R.F.A. (1986):Morphogenic and physiological aberration induced by certain IGRs in the house fly, Musca domestica. Ph. D. Thesis, Fac. Sci. Ainshams Univ.

Carton, B.; Smagghe, G.; Mourad, A.K. and Tirry, T. (1998): Effects of RH-2485 on larvae and pupae of Spodoptera exigua (Hubner). Proc. 50th
Inter. Symposium on Crop Protection, Gent., 63(2b): 53745.

Cerf, D.C. and G.P.Georghiou (1974): Cross resistance to an inhibitor of chitin synthesis TH-6040, in insecticide-resistance strains of the house fly. J. Agr.Food chem. 22(6): 1145-1146.

Darvas, B.; Pap, L.; Kelemen, M. and Polgar, L. A. (1998): Synergistic effects of verbutin with dibenzoyllydrazine-type ecdysteroid agonists on larvae of Aedes aegypti (Diptra: Culicidae). J. Econ. Entomol., 91(6): 1260-64.

El- Kordy, M. W. (1985): The effect of some growth regulators on Musca domestica (L.) Ph. D. Thesis, Fac. Agric., Al- Azhar Univ.

Hashem, H.O. and Youssef, N.S. (1991). Developmental changes induced by methanolic extracts of leaves and fruits of Melia azadrach L. on the house fly, Musca domestica vicina. J.Egypt. Ger. Soc. Zool., 3:335352.

Moustafa, Z. K. (1991): Phenotypic variation of certain enzymes induced by some IGRs against the house fly, Musca domestica (L.). Ph. D. Thesis, Fac. Sci., Ain Shams Univ.

Osman, D. A. (1998): Toxological studies on fly populations of Musca domestica in some Egyptian Governorates. M.Sc. Thesis, Fac., Sci. Entomol. Dep. Cairo Univ.

Reid, B. L.; Brock, V. L. and Bennett, G. W. (1994): Development, morphogenetic and reproductive effects of four polycyclic non-isoprenoid juvenoids in the German cockroach (Dictyoptera: Blattellidae). J. Entomol. Sci., 
29: 31-42.

Schaefer, C.H. and Wilder, W.H. (1973). Insect developmental inhibitors.2- Effects on target mosquito species. J. Econ. Entomol., 66:931-916.

Shafi, S.; Naqvi, S. N. H.; and Zia, N. (1987): Effect of diflubenzuron and penfluron (IGRs) on the morphology on Musca domestica (L.) and Blattella germanica (L.). Pakistan J. Zool., 19(1): 85-90.

Shalaby,A.A. S. (1994): Comparative toxicological studies between Insect growth regulators and conventional insecticides used against the house fly Musca domestica vicina L. (Diptera: Muscidae). Econ. Entomology. Pesticides. Ph. D. Fac. Agric. Cairo. Unvi.

Wright, J.E. (1974): Insect growth regulators: Laboratory and filed evaluation of Thompson Hayward TH 6040 against the house fly and the stable fly. J. Econ. Entomol. 67: 746-747.

Youssef, N. S., EI-Deeb, A. S.; Mesbah, M. A.; Zaghloul, X. A. (1990): Evaluation of three insect growth inhibitors against the house fly, Musca domestica. J. Egypt. Ger. Soc, Zool., 2: 47-61. 

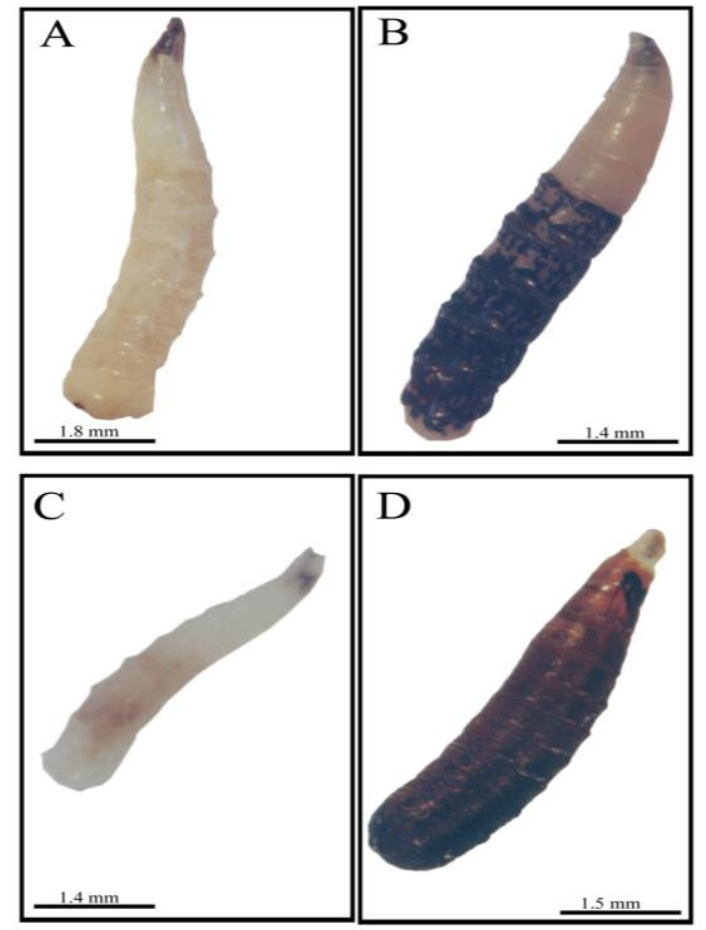

Plate (1): Larvae \& larval-pupal intermediate of M. domestica

Normal larva (untreated)

Malformed larvae: B-treated with consult and admiral .

C- treated with match, mimic and applaud.

D-Malformed larval-pupal intermediate treated with all tested IGRs.

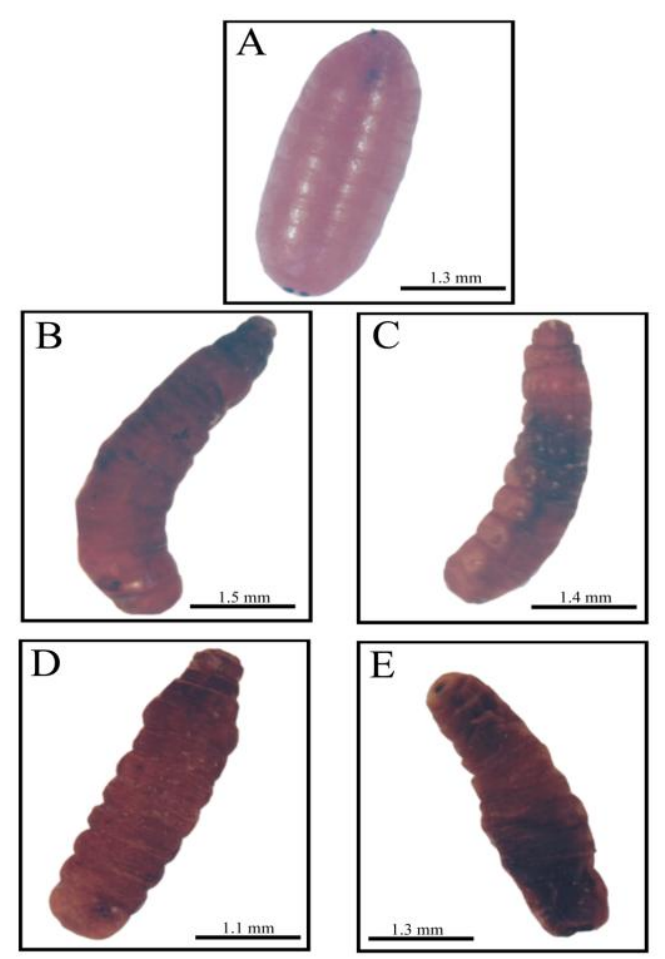

Plate (2): Pupae of $M$. domestica

A-Normal pupa. Malformed pupae:

B- treated with match, consult and mimic. C- treated with applaud and admiral.

D- treated with applaud, consult and mimic, and

E -treated with admiral and match
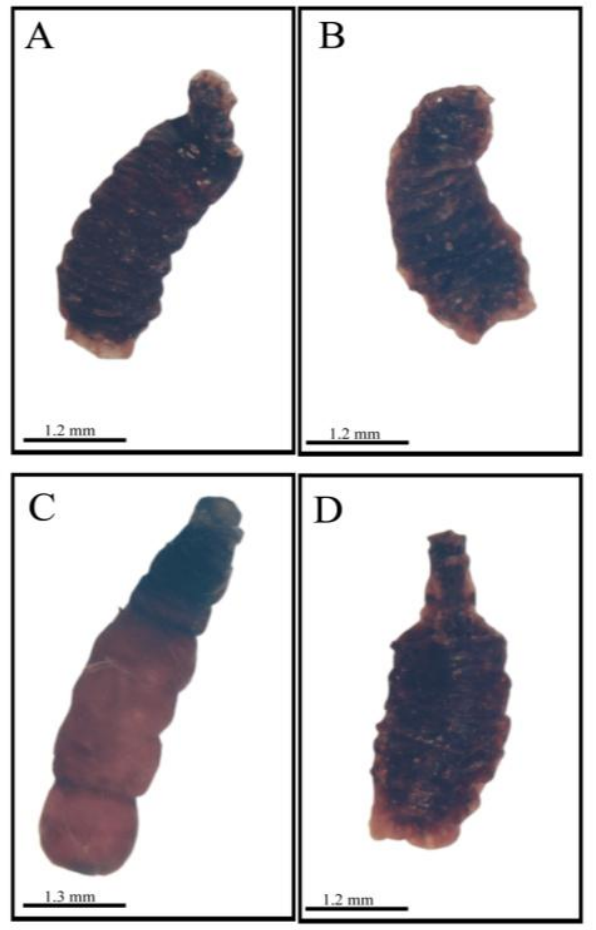

Plate (3): Malformed pupae of M. domestica

Malformed pupae: A- treated with match, admiral and applaud. B- treated with match, consult and mimic. C \& D treated with consult. 

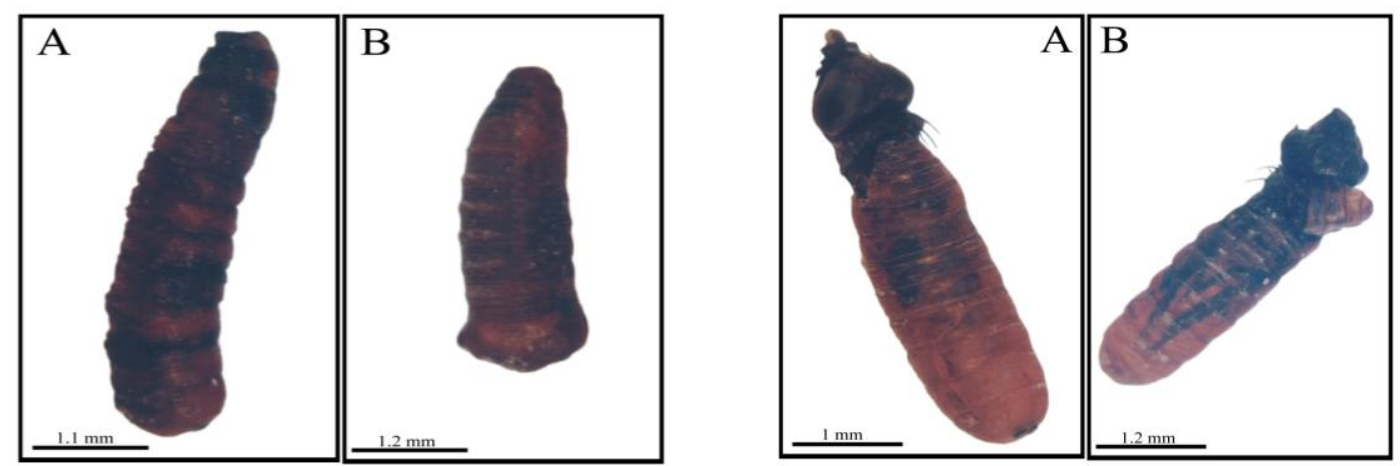

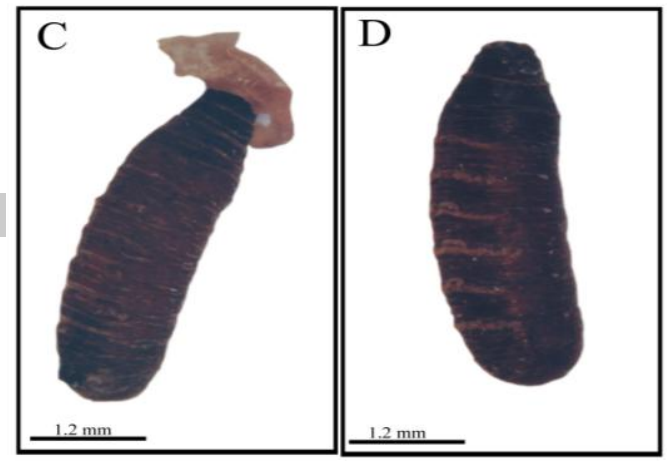

Plate (4): Malformed pupae of M. domestica A-treated with consult and mimic BC- \&D- treated with consult

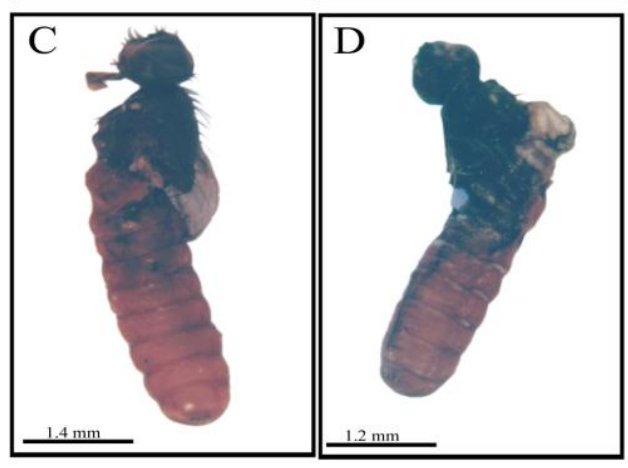

Plate (5): Pupal-adult intermediates of M. domestica, A,B, C and D: Adult which can not emerge completely when treated with all tested IGRs.

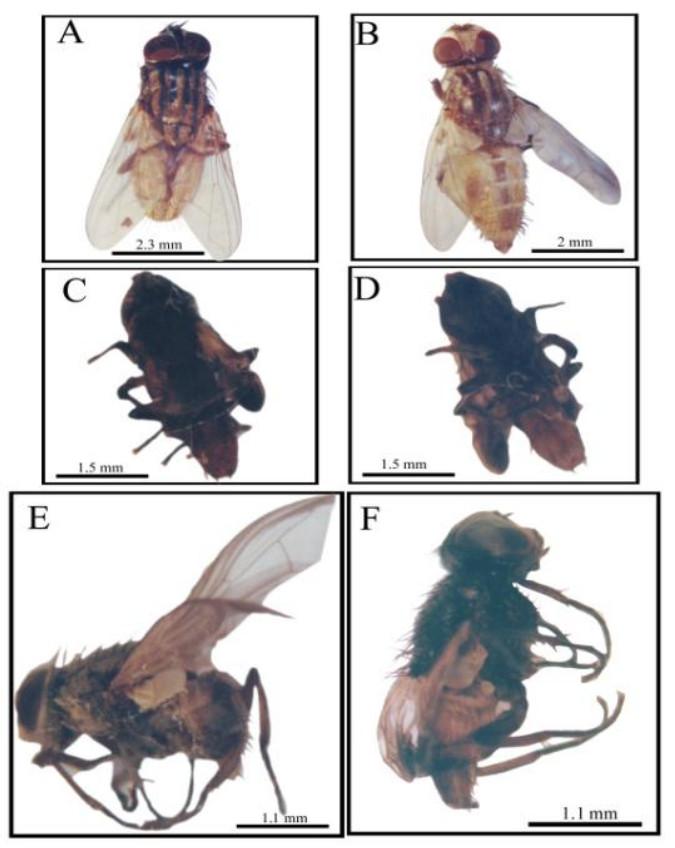

Plate (6): Adult of $M$. domestica

A, B: Normal male and female. Malformed adults: C, D: treated with match, consult and applaud. E-\&F-: treated with mimic and admiral. 


\section{ARABIC SUMMARY}

الآثار المورفولوجية لبعض منظمات النمو الحشرية علي الاببابة المنزلية, مسكا دومستيكا(ذات الجناحين -

$$
\text { مسيدي) (مصدي }
$$

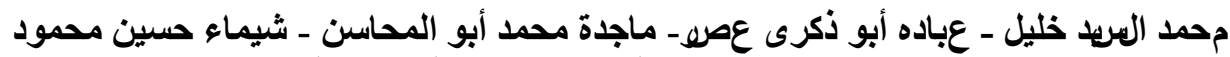
قسم علم الحيوان - كلية العلوم - جامعة مدمة المنوف المدادية

تم اختبار الآثار المورفولوجية لمنظمات النمو الحشرية التالية:-

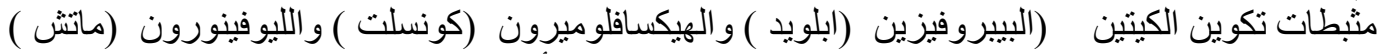

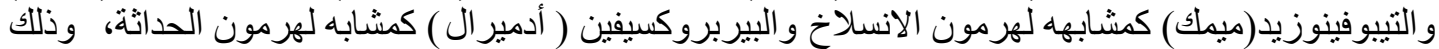

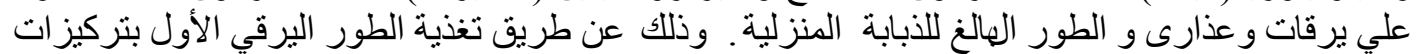

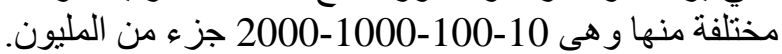

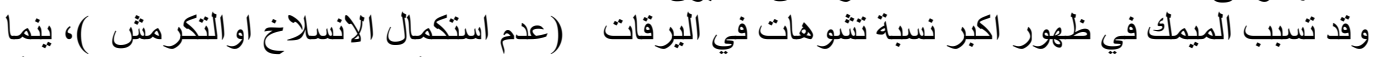

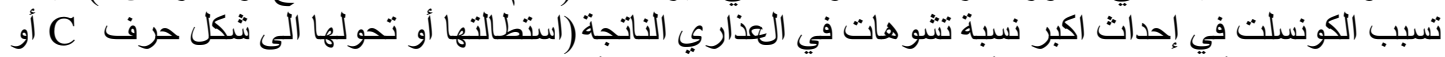

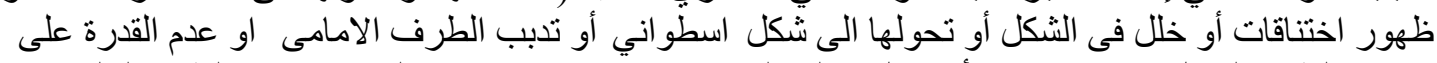

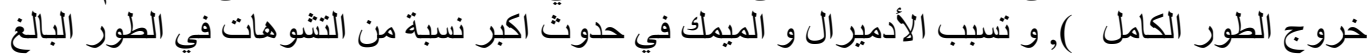

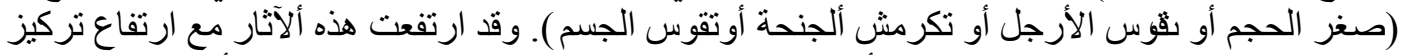

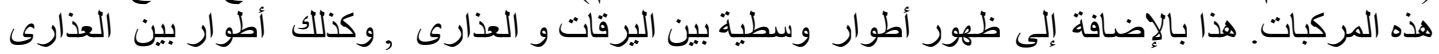

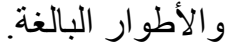

